\title{
Association of Shift Work with Mood Disorders and Sleep Problems According to Chronotype: A 17-year Cohort Study
}

Wan-Ju Cheng $\mathrm{PhD}^{1,2}$, Sampsa Puttonen $\mathrm{PhD}^{3,4}$, Päivi Vanttola $\mathrm{PhD}^{3,5}$, Aki Koskinen $\mathrm{MSc}^{3}$, Mika Kivimäki FMedSci ${ }^{5}$, Mikko Härmä $\mathrm{PhD}^{3}$

${ }^{1}$ Department of Psychiatry, China Medical University Hospital, 2 Yude Road, Taichung, Taiwan

${ }^{2}$ Department of Public Health, China Medical University, 91 Hsueh-Shih Road, Taichung, Taiwan

${ }^{3}$ Finnish Institute of Occupational Health, Topeliuksenkatu 41b, Helsinki, Finland

${ }^{4}$ Institute of Behavioural Sciences, University of Helsinki, Siltavuorenpenger 1A, Helsinki, Finland

${ }^{5}$ Faculty of Medicine, University of Helsinki, Yliopistonkatu 3, Helsinki, Finland

${ }^{*}$ Correspondence to Dr Wan-Ju Cheng

Wan-Ju Cheng, MD., PhD.

Department of Psychiatry, China Medical University Hospital, 2 Yude Road, Taichung, 40447, Taiwan

Tel: +886-4-22052121 ext. 1872

FAX: +886-4-23762003

E-mail: s871065@gmail.com

Word count: 2423 


\section{Funding source}

This paper was supported by the Finnish Academy (grant numbers 323882, 311492), Ministry of Science and Technology, Taiwan (grant numbers 108-2918-I-039-001 and MOST 107-2314-B-039-063-MY3), China Medical University Hospital (grant number DMR-109-247), and NordForsk, the Nordic Program on Health and Welfare (grant numbers 74809,75021 ). The funding sources had no role in the writing of the manuscript or the decision to submit it for publication.

\section{Declaration of Interest}

The authors report no conflict of interest.

\section{Data availability}

The data that support the findings of this study are available from the corresponding author, WJC, upon reasonable request. 


\title{
Association of Shift Work with Mood Disorders and Sleep Problems According to Chronotype: A 17-year Cohort Study
}

\begin{abstract}
Both evening chronotype and shift work are associated with depressive symptoms. This study examined whether the association between shift work and mood disorders and sleep problems varies by chronotype. The study population included 10312 participants from the Finnish Hospital Personnel Cohort Study. Work schedule was assessed using repeated questionnaires between 2000 and 2017. Chronotype, assessed using a single item from the Diurnal Type Scale, was categorized into definite morning, somewhat morning, somewhat evening, and definite evening types. The presence of mood disorders was identified by the 12-item General Health Questionnaire. Sleep problems were assessed by self-reported frequency of difficulty falling asleep and maintaining asleep. Longitudinal fixed effects models were used to examine the associations between shift work and the presence of mood disorders and sleep problems, stratified by chronotype. We found that fixed night work was associated with mood disorders among somewhat evening (adjusted odds ratio [OR] 1.91, 95\% CI 1.09-3.34) and definite evening-type workers (adjusted OR 2.05, 95\% CI 1.06-3.98). Shift work with night shifts was associated with mood disorders among definite evening-type workers (adjusted OR 1.75, 95\% CI 1.18-2.60). Similarly, fixed night work was associated with difficulty maintaining sleep only among evening-type workers. In conclusion, evening chronotype increase the vulnerability to mood disorders and sleep disturbances related to night work.
\end{abstract}

Keywords: Anxiety; depression; sleep; night work; chronotype, morningness; 
eveningness 


\section{Introduction}

Shift work is a prominent environmental feature of contemporary work. Shift work and night work have been found to be associated with an increased risk of poor mental health (Zhao et al. 2019). Disruptions of circadian sleep rhythm, hormone regulation, and metabolic functions are plausible mechanisms underlying the association with adverse mental health outcomes (McClung 2013). The extent to which shift work disrupts the circadian rhythm may be partially dependent on personal preferences of timing for sleep and activity, measured as the chronotype (Roenneberg et al. 2007). Environmental factors are estimated to account for $50 \%-55 \%$ variance in the chronotype (van de Ven et al. 2016), and a review suggested that workers with the late chronotype have better shift work tolerance regarding sleep and alertness than those with morning types, but they had worse work performance, mood, and work satisfaction (Saksvik et al. 2011). In addition, chronotype-adjusted shift scheduling is reported to correlate with longer sleep duration and better sleep quality among shift workers (Vetter et al. 2015), although the effect on mood has not been examined. Shift work provides an opportunity for researchers to explore interactions between environmental light-dark cycle changes and the chronotype and to test links between circadian rhythm disturbance and the development of mental illness.

Recent studies have determined that the evening chronotype is associated with more severe mood symptoms (Au and Reece 2017; Melo et al. 2017), whereas the morning chronotype is associated with positive personality traits (Lipnevich et al. 2017). Advancing sleep time reduced depression, stress, and cognitive and physical performance among people with the evening chronotype (Facer-Childs et al. 2019). Furthermore, chronotype has been observed to affect the relationship between shift work and cancer (Dickerman et al. 2016; Leung L. et al. 2019) and cardiometabolic 
risks (Ritonja et al. 2019). Nevertheless, whether the chronotype modifies the association between shift work and mood disorders remains unclear.

The association between shift work and depressive disorder is often underestimated, because depressive symptoms usually persist for a period before a diagnosis is made. Instead of diagnosis of depressive disorder, many studies have used valid tools to measure mood disorders, including the General Health Questionnaire (GHQ). As a screening tool for mood disorders, including depressive and anxiety disorders (Aalto et al. 2012; Goldberg et al. 1997), the GHQ-12 is also valid for detecting relevant health and productivity issues in the workplace. The GHQ-12 is suitable for detecting shortterm changes in mood disorders in response to work schedules, because it is sensitive to temporal and situational factors (Furnham and Cheng 2019). Furthermore, employees experiencing mood and insomnia symptoms tend to leave shift work and change their work schedule relatively quickly (De Raeve et al. 2009; Driesen et al. 2011). Possible changes in the work schedule during a longer follow-up period are rarely considered in longitudinal studies. Using longitudinal data of work schedules of shift workers, this study aimed to examine associations between shift work and mood disorders as well as the sleep problems of workers with differing chronotypes.

\section{Methods}

\section{Study participants}

Data were obtained from six waves of the Finnish Public Sector (FPS) study between 2000 and 2017. The FPS study comprised two cohorts: the ten-town cohort, a study of local government employees in ten towns, and the Work and Health in Finnish Hospital Personnel Study, a study conducted in 21 hospitals. Response rates were between $67 \%$ and $72 \%$. In this study, due to differences in questionnaire design, only those who 
participated in at least two surveys of the Finnish Hospital Personnel Study were included $(\mathrm{N}=22$ 153). The Ethics Committee of the Hospital District of Helsinki and Uusimaa (HUS) approved the FPS study (HUS 1210/2016), which additionally conforms to the ethics for biological rhythm research on human beings (Portaluppi et al. 2010).

\section{Measurement of working schedule}

In six waves of questionnaires, the participants self-reported their current work schedule either as day work, shift work without night shifts, shift work with night shifts, fixed night work, or other irregular work. Those who reported other irregular work (n $=109$, figure 1) were excluded from this study. The work schedule items used are validated against an objective measure of shift work status based on payroll data (Harma et al. 2017).

\section{Identifying mood disorders and sleep problems}

The presence of mood disorders was detected using the GHQ-12. The participants rated how much they were affected by 12 mood symptoms over the previous few weeks $(0=$ not at all, $1=$ the same as usual, $2=$ rather more than usual, or $3=$ much more than usual). The answers were dichotomized as no distress for 0 and 1, and distressed for 2 and 3. Those who had $\geq 4$ distressed responses were categorized as experiencing mood disorders. A cutoff GHQ-12 score of 3 or 4 has been recommended to screen psychiatric patients from the general population; this cutoff score displayed good sensitivity and specificity in relation to mood and anxiety disorders (Holi et al. 2003).

Sleep problems were assessed based on the reported frequency of having trouble falling asleep or maintaining sleep during the previous 4 weeks (Jenkins et al. 1988). 
The participants chose between not at all, 1-3 days a month, 1 night per week, 2-4 nights per week, 5-6 nights per week, and every day. Sleep problems were defined as experiencing symptoms two or more nights per week, where the reference was $<3$ days a month.

\section{Measurement of chronotype and other variables}

Chronotype was assessed using one item from the Diurnal Type Scale (Torsvall and Akerstedt 1980) in the 2015 survey: "Do you think you are a morning person or an evening person?" The respondents chose between definite morning type, somewhat morning type, somewhat evening type, or definite evening type (Dickerman et al. 2016; Koskenvuo et al. 2007). Self-classified diurnal preference is highly correlated with the chronotype derived from more comprehensive questionnaires (Roenneberg et al. 2007). Chronotype responses were available for 10637 employees who participated in the 2015 survey (Figure 1).

Psychosocial job demands were evaluated using three questions (hard work, insufficient time, and a lot of work) derived from the original Job Content Questionnaire using the job strain model of Karasek and Theorell (Karasek and Theorell 1990). The responses were recorded using a 5-point Likert scale, ranging from 1 (strongly disagree) to 5 (strongly agree), and the mean scores were ranked and divided into tertiles (low, medium, and high).

\section{Statistical analysis}

Distributions of age, gender, sleep problems, and mood disorders by work schedule were determined, and differences were examined using chi-square tests. A fixed effects logistic regression model was used to examine intraindividual associations between 
changes in work schedule and changes in mood disorders as well as sleep problems. A longitudinal, fixed effects model has the advantage that when intraindividual changes over time are examined, time-invariant known and unknown confounders are eliminated (Gunasekara et al. 2014). Thus, the study participants served as their own controls. The interaction effect of the work schedule and chronotype (treated as a timeinvariant variable) on mood disorders was examined. We then stratified the participants by chronotype into four groups (i.e., definite morning type, somewhat morning type, somewhat evening type, or definite evening type), and associations between work schedule and mood disorders were examined for each chronotype group. In crude models, work schedule and survey years were included as time-dependent variables. In the adjusted models, we added working hours and job demands as time-dependent variables. SAS 9.4 was used for all analyses.

\section{Results}

The mean age of the participants was $44.2 \pm 10.4 \mathrm{y}$, and $88.2 \%$ identified themselves as women. The chronotype significantly varied among the four work schedule groups (Table 1), showing that the evening type was more prevalent among night shift workers. The overall prevalence of mood disorders was $21.1 \%$ and did not vary by work schedule. Nevertheless, the prevalence of mood disorders significantly differed by chronotype. Specifically, $20.8 \%, 19.8 \%, 20.6 \%$, and $24.6 \%$ of definite morning-, somewhat morning-, somewhat evening-, and definite evening-type workers, respectively, had mood disorders. The prevalence of sleep problems was significantly different by work schedule; shift work without night shifts showed the highest prevalence of sleep problems.

In fixed effects logit models, a significant interaction effect between shift work 
with night shifts and chronotype was observed, both in the crude model $(p=0.04)$ and the adjusted model $(\mathrm{p}=0.03)$. Fixed night work was associated with mood disorders among somewhat- (OR 2.01, 95\% CI 1.16-3.49) and definite evening-type workers (OR 2.01, 95\% CI 1.06-3.82) (Table 2). The results remained significant after adjusting for working hours and job demands. Shift work with night shifts was significantly associated with mood disorders among definite evening-type workers in both crude (OR 1.90, 95\% CI 1.30-2.78) and adjusted models (OR 1.75, 95\% CI 1.18-2.60). Among somewhat evening-type workers, shift work without night shifts was associated with mood disorders in the crude model, but not in the adjusted model (OR 1.35, 95\% CI $1.00-1.83, \mathrm{p}=0.05)$

Similarly, shift work with night shifts was associated with difficulty falling asleep (Table 3) among definite evening-type workers (adjusted OR 3.62, 95\% CI 2.00-6.56) and somewhat evening-type workers (adjusted OR 2.23, 95\% CI 1.43-3.48). Fixed night work was associated with difficulty maintaining sleep (adjusted OR 2.45, 95\% CI 1.18-5.09) for somewhat evening-type workers. Shift work without night shifts was associated with difficulty falling asleep among somewhat evening-type workers (adjusted OR 1.81, 95\% CI 1.14-2.87). The work schedule was not associated with sleep problems among morning-type workers.

\section{Discussion}

We observed an interaction between shift work and chronotype on mood disorders and sleep problems. Compared with shift workers with the morning chronotype, those with the evening chronotype were more vulnerable to mood disorders and sleep problems.

A systemic review suggested that being an evening-type was positively associated with shift work tolerance in terms of sleep quality, while being a morning-type was 
positively associated with mood and social performance (Saksvik et al. 2011). In the current study, evening-type workers were more likely to report mood disorders or sleep problems than were morning types. To date, few studies have simultaneously examined chronotype, shift work, and mood symptoms. In a small longitudinal study of fastrotating shift nurses, both night work and early chronotype predicted mood symptoms (Bohle and Tilley 1989). Another longitudinal study observed that chronotype was not associated with depressive or anxiety symptoms, but circadian rhythm languidity (difficulties overcoming drowsiness following reduced sleep) was (Thun et al. 2014). Because the evening chronotype is associated with languidity (Baehr et al. 2000; Marcoen et al. 2015), evening-type workers may experience more drowsiness than morning-type workers, which in turn may lead to mood disorders. Although the interaction effect of chronotype and shift work on mental health is inconclusive due to an inadequate number of empirical studies, emerging studies have explored the link between the evening chronotype and mental health.

Our results showed an association between the evening chronotype and mood disorders, which is consistent with findings of several review studies (Au and Reece 2017; Kivela et al. 2018; Melo et al. 2017; Taylor and Hasler 2018). Possible mechanisms for this association include shared genetic factors between the evening chronotype and mood symptoms and a mediating role of insomnia (Au and Reece 2017; Taylor and Hasler 2018). The evening chronotype is associated with poorer sleep quality relative to the morning chronotype among shift workers (Asaoka et al. 2013). However, when sleep conditions and specific shifts are considered, workers with the evening type have shorter sleep duration and worse sleep quality during morning shifts than do those with the morning type (Togo et al. 2017; van de Ven et al. 2016). In this study, evening-type workers had more sleep problems when they worked a shift 
schedule compared with a day work schedule. Because the average percentages of night shift and evening shift were $15 \%$ and $19 \%$, respectively, among the FPS cohort shift workers (Harma et al. 2015), our finding may be explained by evening-type workers experiencing more sleep problems during morning shifts and days off. Findings may differ for workers with a shift schedule that consists of a high percentage of non-day shifts or only a few days off. Nonetheless, the mediating role of sleep problems in the association between shift work and mood disorders remains unclear due to the reciprocal relationship between insomnia and various mood symptoms (Taylor and Hasler 2018).

Another factor that links shift work to the association between the evening chronotype and mood disorders is artificial light exposure. Artificial light exposure suppresses melatonin production (Revell and Skene 2007). Therefore, night shifts would alter melatonin levels and diurnal patterns. Furthermore, evening-type workers are more susceptible to light-at-night disturbance of melatonin secretion than are morning-type workers (Leung M. et al. 2016), and long-term shift work is associated with decreased melatonin secretion only among evening-type workers (Leung M. et al. 2016). Low melatonin secretion is associated with subclinical depressive symptoms and poor sleep (Rahman et al. 2010), which may explain our observation of the vulnerability among evening-type shift workers to mood disorders.

The strengths of this study are that we utilized data collected from a large longitudinal cohort and that we used fixed effects models to control time-invariant factors. Therefore, the association between shift work and mood disorders was not confounded by individual risks of mood disorders, such as childhood traumatic events or genetic vulnerability. However, time-variant confounders not included in the models, such as current stressful life events or major physical illnesses, may confound the results. 
Another limitation is that chronotype was measured using only one question. Therefore, we were unable to determine intraindividual changes in the chronotype over time. Furthermore, we did not use objective tools to measure chronotype, such as dim-light melatonin onset or actigraphy repeated with different shift schedules, to provide more precise information on quantitative changes in chronotype and its relationship with mood symptoms. A third limitation is that we used the GHQ-12 to identify mood disorders, and self-reported questionnaire to identify sleep problems. Detailed mental illness histories and clinical diagnosis were not obtained. Finally, we did not examine the mediating/moderating role of sleep problem in the relationship between work schedule and mood disorders. Statistical models, such as path analysis or structural equation modeling, may be useful in future studies to examine interactions between shift work, sleep, and mood disorders.

In conclusion, an interaction effect between the evening chronotype and shift work on the presence of mood disorders was observed in this study. Evening-chronotype workers were more vulnerable than those with the morning chronotype to shift work exposure regarding mood disorders and sleep problems. Possible mechanisms, including sleep phase changes and melatonin diurnal variations, should be explored in future studies. To improve the mental health of shift workers, the arrangement of shift work schedules should consider their chronotype, and the effect of chronotype-specific strategies aimed at resetting sleep-wake phase on mental health should be examined in future studies.

\section{Funding source}

This paper was supported by the Finnish Academy (grant numbers 323882, 311492),

Ministry of Science and Technology, Taiwan (grant numbers 108-2918-I-039-001 and 
MOST 107-2314-B-039-063-MY3), China Medical University Hospital (grant number DMR-109-247), and NordForsk, the Nordic Program on Health and Welfare (grant numbers 74809,75021 ). The funding sources had no role in the writing of the manuscript or the decision to submit it for publication. 


\section{References}

Aalto AM, Elovainio M, Kivimaki M, Uutela A, Pirkola S. 2012. The Beck Depression Inventory and General Health Questionnaire as measures of depression in the general population: a validation study using the Composite International Diagnostic Interview as the gold standard. Psychiatry Res. 197(1-2): 163-171. doi:10.1016/j.psychres.2011.09.008

Asaoka S, Aritake S, Komada Y, Ozaki A, Odagiri Y, Inoue S, Shimomitsu T, Inoue Y. 2013. Factors associated with shift work disorder in nurses working with rapid-rotation schedules in Japan: the nurses' sleep health project. Chronobiol Int. 30(4): 628-636. doi:10.3109/07420528.2012.762010

Au J, Reece J. 2017. The relationship between chronotype and depressive symptoms: A meta-analysis. J Affect Disord. 218: 93-104. doi:10.1016/j.jad.2017.04.021

Baehr EK, Revelle W, Eastman Cl. 2000. Individual differences in the phase and amplitude of the human circadian temperature rhythm: with an emphasis on morningness-eveningness. J Sleep Res. 9(2): 117-127. Retrieved from https://www.ncbi.nlm.nih.gov/pubmed/10849238

Bohle P, Tilley AJ. 1989. The impact of night work on psychological well-being. Ergonomics. 32(9): 1089-1099.

De Raeve L, Kant I, Jansen NW, Vasse RM, van den Brandt PA. 2009. Changes in mental health as a predictor of changes in working time arrangements and occupational mobility: results from a prospective cohort study. J Psychosom Res. 66(2): 137-145. doi:10.1016/j.jpsychores.2008.05.007

Dickerman BA, Markt SC, Koskenvuo M, Hublin C, Pukkala E, Mucci LA, Kaprio J. 2016. Sleep disruption, chronotype, shift work, and prostate cancer risk and mortality: a 30-year prospective cohort study of Finnish twins. Cancer Causes Control. 27(11): 1361-1370. doi:10.1007/s10552-016-0815-5

Driesen K, Jansen NW, van Amelsvoort LG, Kant I. 2011. The mutual relationship between shift work and depressive complaints--a prospective cohort study. Scand J Work Environ Health. 37(5): 402-410. doi:10.5271/sjweh.3158

Facer-Childs ER, Middleton B, Skene DJ, Bagshaw AP. 2019. Resetting the late timing of 'night owls' has a positive impact on mental health and performance. Sleep Med. 60: 236-247. doi:10.1016/j.sleep.2019.05.001

Furnham A, Cheng H. 2019. GHQ score changes from teenage to young adulthood. J Psychiatr Res. 113: 46-50. doi:10.1016/j.jpsychires.2019.03.006

Goldberg DP, Gater R, Sartorius N, Ustun TB, Piccinelli M, Gureje O, Rutter C. 1997. The validity of two versions of the GHQ in the WHO study of mental illness in general health care. Psychological Medicine. 27(1): 191-197. doi:10.1017/S0033291796004242

Gunasekara Fl, Richardson K, Carter K, Blakely T. 2014. Fixed effects analysis of repeated measures data. Int J Epidemiol. 43(1): 264-269. doi:10.1093/ije/dyt221

Harma M, Koskinen A, Ropponen A, Puttonen S, Karhula K, Vahtera J, Kivimaki M. 2017. Validity of self-reported exposure to shift work. Occup Environ Med. 74(3): 228-230. doi:10.1136/oemed-2016-103902

Harma M, Ropponen A, Hakola T, Koskinen A, Vanttola P, Puttonen S, Sallinen M, Salo P, Oksanen T, Pentti J, et al. 2015. Developing register-based measures for assessment of working time patterns for epidemiologic studies. Scand J Work 
Environ Health. 41(3): 268-279. doi:10.5271/sjweh.3492

Holi MM, Marttunen M, Aalberg V. 2003. Comparison of the GHQ-36, the GHQ-12 and the SCL-90 as psychiatric screening instruments in the Finnish population. Nord J Psychiatry. 57(3): 233-238. doi:10.1080/08039480310001418

Jenkins CD, Stanton BA, Niemcryk SJ, Rose RM. 1988. A scale for the estimation of sleep problems in clinical research. J Clin Epidemiol. 41(4): 313-321. Retrieved from https://www.ncbi.nlm.nih.gov/pubmed/3351539

Karasek R, Theorell Tr. (1990). Healthy work : stress, productivity, and the reconstruction of working life. New York: Basic Books.

Kivela L, Papadopoulos MR, Antypa N. 2018. Chronotype and Psychiatric Disorders. Curr Sleep Med Rep. 4(2): 94-103. doi:10.1007/s40675-018-0113-8

Koskenvuo M, Hublin C, Partinen M, Heikkila K, Kaprio J. 2007. Heritability of diurnal type: a nationwide study of 8753 adult twin pairs. J Sleep Res. 16(2): 156-162. doi:10.1111/j.1365-2869.2007.00580.x

Leung L, Grundy A, Siemiatycki J, Arseneau J, Gilbert L, Gotlieb WH, Provencher DM, Aronson KJ, Koushik A. 2019. Shift Work Patterns, Chronotype, and Epithelial Ovarian Cancer Risk. Cancer Epidemiol Biomarkers Prev. 28(5): 987-995. doi:10.1158/1055-9965.EPI-18-1112

Leung M, Tranmer J, Hung E, Korsiak J, Day AG, Aronson KJ. 2016. Shift Work, Chronotype, and Melatonin Patterns among Female Hospital Employees on Day and Night Shifts. Cancer Epidemiol Biomarkers Prev. 25(5): 830-838. doi:10.1158/1055-9965.EPI-15-1178

Lipnevich AA, Crede M, Hahn E, Spinath FM, Roberts RD, Preckel F. 2017. How distinctive are morningness and eveningness from the Big Five factors of personality? A meta-analytic investigation. J Pers Soc Psychol. 112(3): 491509. doi:10.1037/pspp0000099

Marcoen N, Vandekerckhove M, Neu D, Pattyn N, Mairesse O. 2015. Individual differences in subjective circadian flexibility. Chronobiol Int. 32(9): 1246-1253. doi:10.3109/07420528.2015.1085387

McClung CA. 2013. How might circadian rhythms control mood? Let me count the ways. Biol Psychiatry. 74(4): 242-249. doi:10.1016/j.biopsych.2013.02.019

Melo MCA, Abreu RLC, Linhares Neto VB, de Bruin PFC, de Bruin VMS. 2017. Chronotype and circadian rhythm in bipolar disorder: A systematic review. Sleep Med Rev. 34: 46-58. doi:10.1016/j.smrv.2016.06.007

Portaluppi F, Smolensky MH, Touitou Y. 2010. Ethics and methods for biological rhythm research on animals and human beings. Chronobiol Int. 27(9-10): 1911-1929. doi:10.3109/07420528.2010.516381

Rahman SA, Marcu S, Kayumov L, Shapiro CM. 2010. Altered sleep architecture and higher incidence of subsyndromal depression in low endogenous melatonin secretors. Eur Arch Psychiatry Clin Neurosci. 260(4): 327-335. doi:10.1007/s00406-009-0080-7

Revell VL, Skene DJ. 2007. Light-induced melatonin suppression in humans with polychromatic and monochromatic light. Chronobiol Int. 24(6): 1125-1137. doi:10.1080/07420520701800652

Ritonja J, Tranmer J, Aronson KJ. 2019. The relationship between night work, chronotype, and cardiometabolic risk factors in female hospital employees. Chronobiol Int. 36(5): 616-628. doi:10.1080/07420528.2019.1570247 
Roenneberg T, Kuehnle T, Juda M, Kantermann T, Allebrandt K, Gordijn M, Merrow M. 2007. Epidemiology of the human circadian clock. Sleep Med Rev. 11(6): 429438. doi:10.1016/j.smrv.2007.07.005

Saksvik IB, Bjorvatn B, Hetland H, Sandal GM, Pallesen S. 2011. Individual differences in tolerance to shift work--a systematic review. Sleep Med Rev. 15(4): 221235. doi:10.1016/j.smrv.2010.07.002

Taylor BJ, Hasler BP. 2018. Chronotype and Mental Health: Recent Advances. Curr Psychiatry Rep. 20(8): 59. doi:10.1007/s11920-018-0925-8

Thun E, Bjorvatn B, Torsheim T, Moen BE, Magerøy N, Pallesen S. 2014. Night work and symptoms of anxiety and depression among nurses: A longitudinal study. Work \& Stress. 28(4): 376-386. doi:10.1080/02678373.2014.969362

Togo F, Yoshizaki T, Komatsu T. 2017. Association between depressive symptoms and morningness-eveningness, sleep duration and rotating shift work in Japanese nurses. Chronobiol Int. 34(3): 349-359. doi:10.1080/07420528.2016.1273942

Torsvall L, Akerstedt T. 1980. A diurnal type scale. Construction, consistency and validation in shift work. Scand J Work Environ Health. 6(4): 283-290. Retrieved from https://www.ncbi.nlm.nih.gov/pubmed/7195066

van de Ven HA, van der Klink JJ, Vetter C, Roenneberg T, Gordijn M, Koolhaas W, de Looze MP, Brouwer S, Bultmann U. 2016. Sleep and need for recovery in shift workers: do chronotype and age matter? Ergonomics. 59(2): 310-324. doi:10.1080/00140139.2015.1058426

Vetter C, Fischer D, Matera JL, Roenneberg T. 2015. Aligning work and circadian time in shift workers improves sleep and reduces circadian disruption. Curr Biol. 25(7): 907-911. doi:10.1016/j.cub.2015.01.064

Zhao Y, Richardson A, Poyser C, Butterworth P, Strazdins L, Leach LS. 2019. Shift work and mental health: a systematic review and meta-analysis. Int Arch Occup Environ Health. 92(6): 763-793. doi:10.1007/s00420-019-01434-3 
Table 1. Baseline distribution of chronotype, mood disorders, and sleep conditions by work schedule $(\mathrm{N}=10637)$.

\begin{tabular}{|c|c|c|c|c|c|}
\hline & $\begin{array}{r}\text { Day work } \\
(\mathrm{N}=4973)\end{array}$ & $\begin{array}{l}\text { Shift work without } \\
\text { night shifts }(N=1419)\end{array}$ & $\begin{array}{c}\text { Shift work with night } \\
\text { shifts }(\mathrm{N}=3997)\end{array}$ & $\begin{array}{l}\text { Fixed night work } \\
(\mathrm{N}=\mathbf{2 4 8})\end{array}$ & $\mathbf{p}$ \\
\hline & $\mathbf{N}(\%)$ & $\mathbf{N}(\%)$ & $\mathbf{N}(\%)$ & $\mathbf{N}(\%)$ & \\
\hline \multicolumn{6}{|l|}{ Age (y) } \\
\hline$\leq 39$ & $1294(26.02 \%)$ & $411(28.96 \%)$ & $1717(42.96 \%)$ & $55(22.18 \%)$ & $<0.001$ \\
\hline $40-49$ & $1537(30.91 \%)$ & $446(31.43 \%)$ & $1152(28.82 \%)$ & $91(36.69 \%)$ & $<0.001$ \\
\hline$\geq \mathbf{5 0}$ & $2142(43.07 \%)$ & $562(39.61 \%)$ & $1128(28.22 \%)$ & $102(41.13 \%)$ & $<0.001$ \\
\hline Gender (Women) & $4191(84.28 \%)$ & $1333(93.94 \%)$ & $3633(90.89 \%)$ & $221(89.11 \%)$ & $<0.001$ \\
\hline Chronotype & & & & & $<0.001$ \\
\hline Definite morningness & $1108(22.28 \%)$ & $309(21.78 \%)$ & $362(14.06 \%)$ & $33(13.31 \%)$ & \\
\hline Somewhat morningness & $1527(30.71 \%)$ & $395(27.84 \%)$ & $1020(25.52 \%)$ & $70(28.23 \%)$ & \\
\hline Somewhat eveningness & $1614(32.46 \%)$ & $495(34.88 \%)$ & $1477(36.95 \%)$ & $76(30.65 \%)$ & \\
\hline Definite eveningness & $724(14.56 \%)$ & $220(15.50 \%)$ & $938(23.47 \%)$ & $69(27.82 \%)$ & \\
\hline Mood disorders & $1054(21.27 \%)$ & $319(22.51 \%)$ & $815(20.46 \%)$ & $54(21.77 \%)$ & 0.42 \\
\hline Difficulty falling asleep & $443(8.91 \%)$ & $185(13.04 \%)$ & $465(11.63 \%)$ & $23(9.27 \%)$ & $<0.001$ \\
\hline Difficulty maintaining asleep & $909(18.28 \%)$ & $309(21.78 \%)$ & $586(14.66 \%)$ & $40(16.13 \%)$ & $<0.001$ \\
\hline
\end{tabular}


Table 2. Odds ratio (OR) and $95 \%$ confidence interval (CI) of work schedule (day work as reference) for mood disorders in fixed effects model, stratified by chronotype $(\mathrm{N}=10637)$.

\begin{tabular}{|c|c|c|c|c|c|}
\hline & $\begin{array}{c}\text { All participants } \\
\left(N^{b}=4264\right)\end{array}$ & $\begin{array}{c}\begin{array}{c}\text { Definite morning } \\
(\mathrm{N}=800)\end{array} \\
\text { OR }(95 \% \mathrm{CI})\end{array}$ & $\begin{array}{c}\begin{array}{c}\text { Somewhat morning } \\
(\mathrm{N}=1207)\end{array} \\
\text { OR }(95 \% \mathrm{CI})\end{array}$ & $\begin{array}{c}\begin{array}{c}\text { Somewhat evening } \\
(\mathrm{N}=1427)\end{array} \\
\mathrm{OR}(95 \% \mathrm{CI})\end{array}$ & $\begin{array}{c}\begin{array}{c}\text { Definite Evening } \\
(\mathrm{N}=830)\end{array} \\
\text { OR }(95 \% \mathrm{CI})\end{array}$ \\
\hline \multicolumn{6}{|l|}{ Crude model } \\
\hline Shift work without night shifts & $1.11(0.94-1.32)$ & $1.02(0.71-1.46)$ & $1.01(0.74-1.37)$ & $1.37(1.02-1.84)^{\mathrm{c}}$ & $1.04(0.69-1.57)$ \\
\hline Shift work with night shifts & $1.21(1.03-1.43)^{\mathrm{c}}$ & $1.03(0.71-1.49)$ & $1.08(0.79-1.47)$ & $1.15(0.87-1.52)$ & $1.90(1.30-2.78)^{\mathrm{c}}$ \\
\hline Fixed night work & $1.55(1.10-2.16)^{\mathrm{c}}$ & $1.46(0.58-3.69)$ & $0.93(0.42-2.05)$ & $2.01(1.16-3.49)^{\mathrm{c}}$ & $2.01(1.06-3.82)^{\mathrm{c}}$ \\
\hline \multicolumn{6}{|l|}{ Adjusted model ${ }^{a}$} \\
\hline Shift work without night shifts & $1.08(0.91-1.28)$ & $0.98(0.68-1.41)$ & $0.98(0.72-1.35)$ & $1.35(1.00-1.83)$ & $1.02(0.67-1.56)$ \\
\hline Shift work with night shifts & $1.12(0.95-1.32)$ & $0.95(0.65-1.38)$ & $0.98(0.72-1.35)$ & $1.11(0.83-1.47)$ & $1.75(1.18-2.60)^{\mathrm{c}}$ \\
\hline Fixed night work & $1.50(1.06-2.12)^{\mathrm{c}}$ & $1.56(0.60-4.07)$ & $0.87(0.39-1.93)$ & $1.91(1.09-3.34)^{\mathrm{c}}$ & $2.05(1.06-3.98)^{\mathrm{c}}$ \\
\hline
\end{tabular}

${ }^{\mathrm{a}}$ Adjusted for job demands and working hours.

${ }^{b}$ Number of participants with a change in the presence of mood disorder between any two waves of the survey.

${ }^{c} \mathrm{p}<0.05$ 
Table 3. Odds ratio (OR) of work schedule (day work as reference) for sleep problems in fixed effects model, stratified by chronotype (N $=10$ 637).

\begin{tabular}{|c|c|c|c|c|c|}
\hline & $\begin{array}{l}\text { All participants } \\
\left(N^{b}=1946\right)\end{array}$ & $\begin{array}{l}\text { Definite morning } \\
\quad(\mathrm{N}=341)\end{array}$ & $\begin{array}{l}\text { Somewhat morning } \\
\quad(\mathrm{N}=513)\end{array}$ & $\begin{array}{l}\text { Somewhat evening } \\
\quad(N=665)\end{array}$ & $\begin{array}{l}\text { Definite Evening } \\
\quad(\mathrm{N}=427)\end{array}$ \\
\hline $\begin{array}{l}\text { Outcome as difficulty falling } \\
\text { asleep }\end{array}$ & OR $(95 \% \mathrm{CI})$ & OR $(95 \% C I)$ & OR (95\%CI) & OR $(95 \% C I)$ & OR $(95 \% \mathrm{CI})$ \\
\hline Shift work without night shift & 1.32( & 40) & 78) & $1.81(1$. & 1.68 \\
\hline Shift work with night shifts & $1.75(1.36-2.26)^{\mathrm{c}}$ & $1.03(0.57-1.85)$ & $1.05(0.64-1.73)$ & $2.23(1.43-3.48)^{\mathrm{c}}$ & $3.62(2.00-6.56)^{\mathrm{c}}$ \\
\hline Fixed night work & $1.56(0.91-2.67)$ & $2.56(0.70-9.39)$ & $0.58(0.13-2.50)$ & $2.50(0.94-6.62)$ & $1.96(0.74-5.20)$ \\
\hline
\end{tabular}

Fixed night work

All participants Definite morning Somewhat morning Somewhat evening

$(\mathbf{N}=\mathbf{2 9 7 4})$

Outcome as difficulty

maintaining asleep

\section{Shift work without night shifts}

Shift work with night shifts

OR (95\%CI)
Definite mor
$(\mathrm{N}=649)$

OR $(95 \% \mathrm{CI})$

$(\mathbf{N}=903)$

$$
\text { OR (95\%CI) }
$$

$0.64(0.41-1.00)$
$0.93(0.57-1.50)$

$0.93(0.57-1.50)$

$1.26(0.84-1.89)$

$0.94(0.63-1.40)$

$0.42(0.14-1.21)$

$1.17(0.94-1.45)$
$1.10(0.71-1.69)$

${ }^{a}$ Models were adjusted for working hours and job demands.

${ }^{b}$ Number of participants with a change in the presence of sleep problems between any two waves of the survey. ${ }^{c} \mathrm{p}<0.05$ 
Figure 1. Flow chart of study participant selection.

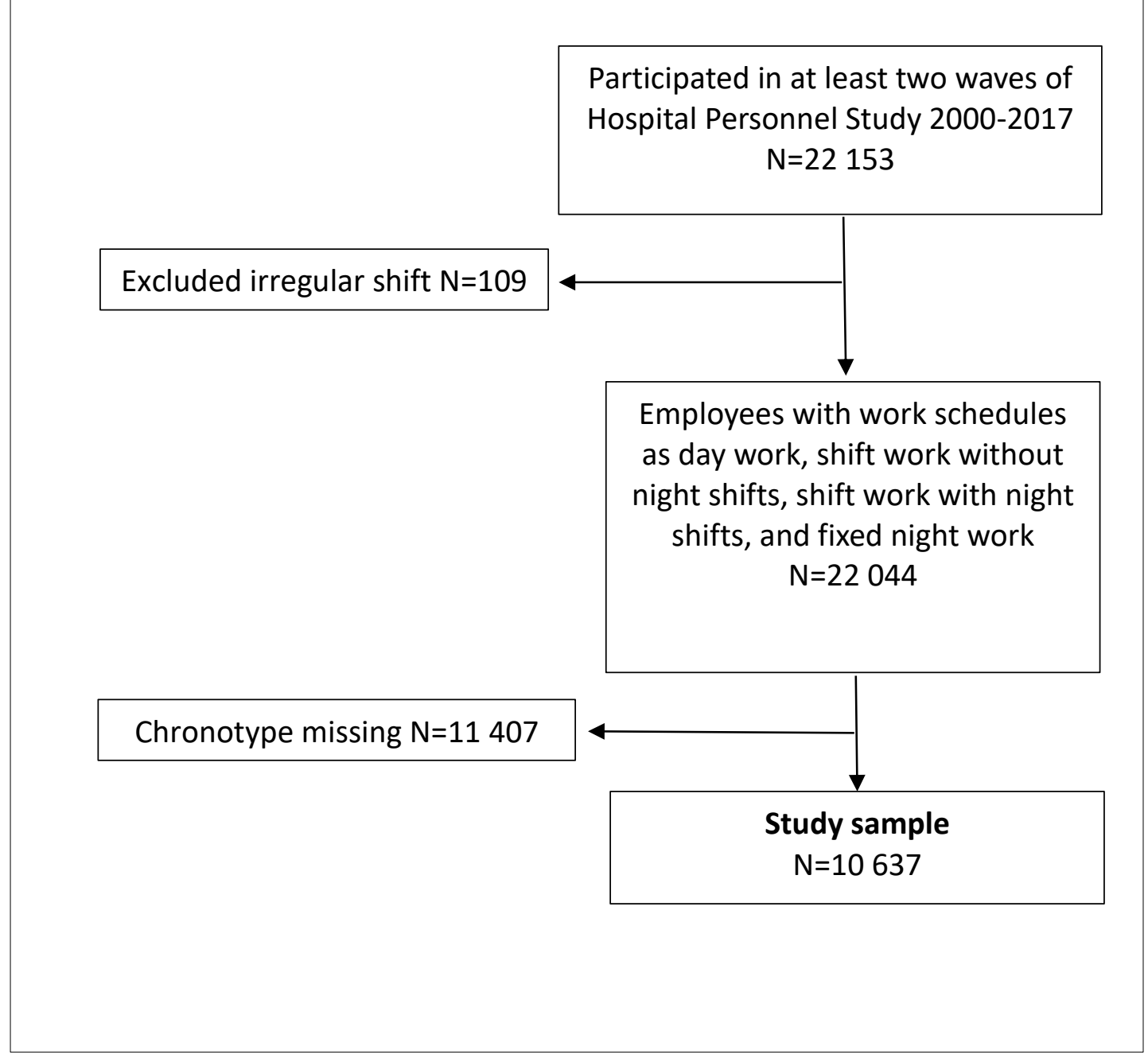

